\title{
The Impact of Prematurity on Morbidity and Mortality in Newborns with Dextro-transposition of the Great Arteries
}

\author{
Vinzenz Boos ${ }^{1,2,3}$ (1) $\cdot$ Christoph Bührer ${ }^{2} \cdot$ Mi-Young Cho ${ }^{4} \cdot$ Joachim Photiadis ${ }^{4} \cdot$ Felix Berger $^{1,5}$
}

Received: 19 June 2021 / Accepted: 9 September 2021 / Published online: 24 September 2021

(c) The Author(s) 2021

\begin{abstract}
Prematurity is a risk factor for adverse outcomes after arterial switch operation in newborns with D-TGA (D-TGA). In this study, we sought to investigate the impact of prematurity on postnatal and perioperative clinical management, morbidity, and mortality during hospitalization in neonates with simple and complex D-TGA who received arterial switch operation (ASO). Monocentric retrospective analysis of 100 newborns with D-TGA. Thirteen infants (13.0\%) were born premature. Preterm infants required significantly more frequent mechanical ventilation in the delivery room $(69.2 \%$ vs. $34.5 \%, p=0.030)$ and during the preoperative course $(76.9 \%$ vs. $37.9 \%, p=0.014)$. Need for inotropic support $(30.8 \%$ vs. $8.0 \%, p=0.035)$ and red blood cell transfusions $(46.2 \%$ vs. $10.3 \%, p=0.004)$ was likewise increased. Preoperative mortality $(23.1 \%$ vs $0.0 \%$, $p=0.002$ ) was significantly increased in preterm infants, with necrotizing enterocolitis as cause of death in two of three infants. In contrast, mortality during and after surgery did not differ significantly between the two groups. Cardiopulmonary bypass times were similar in both groups (median $275 \mathrm{vs.} 263 \mathrm{~min}, p=0.322$ ). After ASO, arterial lactate ( $34.5 \mathrm{vs} .21 .5 \mathrm{mg} /$ $\mathrm{dL}, p=0.007$ ), duration of mechanical ventilation (median $175 \mathrm{vs.} 106 \mathrm{~h}, p=0.038)$, and venous thrombosis $(40.0 \%$ vs. $4.7 \%, p=0.004$ ) were increased in preterm, as compared to term infants. Gestational age (adjusted unit odds ratio 0.383 , $95 \%$ confidence interval $0.179-0.821, p=0.014$ ) was independently associated with mortality. Prematurity is associated with increased perioperative morbidity and increased preoperative mortality in D-TGA patients.
\end{abstract}

Keywords Arterial switch operation $\cdot$ Mortality $\cdot$ Prematurity $\cdot$ Transposition of the great arteries

\section{Introduction}

Congenital heart disease (CHD) and prematurity are two of the leading causes of perinatal mortality [1]. Premature infants with CHD have a particularly increased risk for

Vinzenz Boos

boos@dhzb.de

1 Department of Congenital Heart Disease/Pediatric Cardiology, German Heart Center Berlin, Augustenburger Platz 1, 13353 Berlin, Germany

2 Department of Neonatology, Charité - Universitätsmedizin Berlin, Berlin, Germany

3 Department of Neonatology, Hospital Zollikerberg, Zollikerberg, Switzerland

4 Department of Congenital Heart Surgery / Pediatric Heart Surgery, German Heart Center Berlin, Berlin, Germany

5 German Center for Cardiovascular Research (DZHK), Congenital Heart Diseases, Partner Site Berlin, Berlin, Germany morbidity and mortality [2]. Infants with complex cardiovascular malformations are twice as likely to be born premature. However, dextro-transposition of the great arteries (D-TGA) has one of the lowest defect-specific percentages of premature births of about 8-11\%, comparable to the risk of prematurity in infants without CHD $[1,3]$.

D-TGA requires anatomical repair in the neonatal period. The arterial switch operation (ASO) is the surgical treatment of choice with low perioperative mortality $[4,5]$. ASO is typically performed shortly after birth, and delay of surgery is associated with increased morbidity and mortality [6]. Prematurity has been described as risk factor for perioperative morbidity, increased length of postoperative hospitalization, and in-hospital mortality in newborns with D-TGA [7-10]. In addition, premature infants with D-TGA are likely to be of low birth weight. Although ASO can be performed in neonates with a weight below $2000 \mathrm{~g}$, the rates for perioperative morbidities and mortality are increased compared to infants weighing more than $2000 \mathrm{~g}[11,12]$. 
The management of premature infants with D-TGA, and complex CHD in general, presents numerous challenges related to inadequate maturation of multiple organ systems. They include the postnatal transition, hemodynamic and respiratory stabilization, including definition of target values for oxygenation and (permissive) hypercapnia, optimal nutrition, fluid and electrolyte management, prevention of infections and gastrointestinal, neurological, pulmonary, and renal complications. Furthermore, optimal timing for cardiac surgery is crucial to optimize perioperative outcomes [12, 13].

There are limited data on perioperative, particularly postnatal, preoperative morbidities, and mortality in premature infants with D-TGA. Previous studies investigated more heterogeneous cohorts of newborns with various types of complex CHD or focused mainly on operative outcomes [7, 14, 15]. The purpose of this study was to assess the impact of prematurity on postnatal, mainly preoperative medical treatment, as well as morbidity and mortality during hospitalization in infants with D-TGA in a single institutional cohort.

\section{Patients and Methods}

We included all newborns diagnosed with D-TGA, both with and without associated cardiac lesions such as septal defects or coarctation, who were born between January 2013 and December 2017, and whose planned surgical therapy was ASO. All perinatal and perioperative data were retrieved from medical files and operative notes. The study received approval by the institutional review board (\# EA2/069/17). The study cohort was divided into two groups for comparison: infants who were born before 37 completed weeks of gestational age were assigned to the "premature group," whereas term born infants were assigned to the control group.

For infants with prenatal diagnosis of D-TGA, neonatologists and pediatric cardiologists were present in the delivery room. Infants who were born in external hospitals without prenatal diagnosis of D-TGA were transferred to our units shortly after diagnosis. All patients who survived the preoperative period subsequently received ASO in our institution, including the repair of associated lesions, if present.

The following data were analyzed for each patient: (1) demographic data, including sex, gestational age, birth weight, and multiple pregnancies; (2) obstetric data, including maternal age, administration of antenatal steroids, and premature rupture of membranes; (3) data on postnatal adaptation, including umbilical arterial blood $\mathrm{pH}$, Apgar scores, and neonatal management in the delivery room; (4) preoperative management, such as inotropic support, mechanical ventilation, and co-morbidities, including modified Bell stage IIa or higher necrotizing enterocolitis (NEC), intracranial hemorrhage, suspected infection, based on clinical signs and laboratory tests, and preoperative mortality; (5) cardiac anatomy and coronary artery pattern; (6) operative data, including age and weight at surgery, transfusion during the course of cardiopulmonary bypass (CPB), and intraoperative death; (7) details on postoperative treatment, such as extracorporeal membrane oxygenation (ECMO), cardiac arrhythmia requiring medication or pacing, duration of postoperative ventilation, postoperative co-morbidities, including NEC and culture-proven sepsis, and postoperative mortality; (8) duration of hospitalization and overall mortality.

All missing information are noted in the results tables. All statistical analyses were conducted using R studio v1.4.1106 (RStudio, Boston, MA) with R v4.0.4 (The R Foundation for Statistical Computing, Vienna, Austria). Descriptive data for continuous variables are presented as median and interquartile range. Categorical variables are presented as relative frequencies. Comparison between groups (premature vs. term born) was chosen, as the relatively small number of patients in this single-center study impedes analysis by gestational age. Differences for continuous variables between the two groups were analyzed using Wilcoxon rank sum test, and Fisher's exact test was used for comparison of dichotomous variables. Multivariable analysis was conducted on variables that reached significance with $p$ value $\leq 0.1$ in univariate analysis, using a logistic regression model, with demographics, maternal, and anatomic variables as input variables and mortality as output variable. Odds ratios (OR) are presented with 95\% confidence interval (CI) and Nagelkerke's $\mathrm{R}$-squared is reported (goodness-of-fit). A $p$ value $<0.05$ was considered statistically significant.

\section{Results}

Inclusion criteria were met by 100 neonates. 13 of these $(13 \%)$ were premature born infants, all remaining infants were born at term (37 0/7 to $416 / 7$ weeks of gestational age). No infant was born post term (42 0/7 weeks of gestational age and older). The only outborn patient in the cohort, a preterm infant, was diagnosed with D-TGA on the first day of life and transferred on the second day of life. Premature infants had a lower birth weight (2300 vs. $3280 \mathrm{~g}$, $p<0.001)$ and received more often antenatal steroids (38.5\% vs. $1.1 \%, p<0.001)$. We observed a trend toward more Cesarean deliveries in preterm infants $(61.5 \%$ vs. $32.2 \%$, $p=0.061)$ and prematures required significantly more frequent mechanical ventilation in the delivery room $(69.2 \%$ vs. $34.5 \%, p=0.030$ ), as compared to term babies (Table 1).

Cardiac anatomy and coronary artery pattern were similarly distributed in premature and term infants. The majority 
Table 1 Demographic characteristics, obstetric data, and postnatal adaptation

\begin{tabular}{|c|c|c|c|}
\hline Variable & $\begin{array}{l}\text { Premature infants }(n=13) \\
\text { Patients }(\%) \text { or median (IQR) }\end{array}$ & $\begin{array}{l}\text { Term neonates }(n=87) \\
\text { Patients }(\%) \text { or median (IQR) }\end{array}$ & $p$ value \\
\hline \multicolumn{4}{|l|}{ Demographics } \\
\hline Sex, male & $10(76.9)$ & $55(63.2)$ & 0.534 \\
\hline Gestational age (weeks) & $35.1(33.3-36.3)$ & $39.1(38.4-40.0)$ & $<0.001$ \\
\hline Birth weight $(\mathrm{g})$ & $2300(1850-2515)$ & $3280(3008-3565)$ & $<0.001$ \\
\hline Multiple gestation & $3(23.1)$ & $2(2.3)$ & 0.015 \\
\hline Genetic abnormality & $0(0.0)$ & $1(1.1)$ & 1.000 \\
\hline Extracardiac malformation & $0(0.0)$ & $8(9.2)$ & 0.592 \\
\hline Prenatal diagnosis of CHD & $11(84.6)$ & $75(86.2)$ & 1.000 \\
\hline Age at postnatal diagnosis of CHD (days) ${ }^{a}$ & $1(1-1)$ & $1(1-2)$ & 0.331 \\
\hline \multicolumn{4}{|l|}{ Obstetric data } \\
\hline Maternal age (years) & $31(28-31)$ & $30(26-35)$ & 0.565 \\
\hline Antenatal steroids & $5(38.5)$ & $1(1.1)$ & $<0.001$ \\
\hline Premature rupture of membranes & $1(7.7)$ & $1(1.1)$ & 0.244 \\
\hline Cesarean delivery & $8(61.5)$ & $28(32.2)$ & 0.061 \\
\hline \multicolumn{4}{|l|}{ Postnatal adaptation } \\
\hline Umbilical arterial blood $\mathrm{pH}^{\mathrm{a}}$ & $7.27(7.24-7.30)$ & $7.28(7.25-7.32)$ & 0.591 \\
\hline Apgar at $5 \min ^{\mathrm{a}}$ & $8(7-9)$ & $9(8-9)$ & 0.257 \\
\hline Apgar at $10 \mathrm{~min}^{\mathrm{a}}$ & $8.5(8-9)$ & $9(8-9)$ & 0.416 \\
\hline Meconium aspiration & $0(0.0)$ & $0(0.0)$ & N/A \\
\hline Respiratory support in DR & $10(76.9)$ & $54(62.1)$ & 0.367 \\
\hline Mechanical ventilation in DR & $9(69.2)$ & $30(34.5)$ & 0.030 \\
\hline Cardiopulmonary resuscitation in DR & $1(7.7)$ & $4(4.6)$ & 0.509 \\
\hline
\end{tabular}

$C H D$ congenital heart disease, $D R$ delivery room, $I Q R$ interquartile range, $N / A$ not applicable

${ }^{a}$ The following information (no. of infants) was missing: Umbilical arterial blood pH 1, Apgar score at 5 min =1, and Apgar score at 10 min =1 in the "premature infants" group; age at postnatal diagnosis of $\mathrm{CHD}=1$ in the control group

of infants had isolated D-TGA and usual coronary artery pattern (1L,Cx;2R) (Table 2).

All infants received intravenous Prostaglandin E1 to maintain ductal patency. The rate of balloon atrial septostomy was equally high in both groups (76.9\% vs. $82.8 \%$, $p=0.699$ ) and performed at median day 1 of life. More co-morbidities were observed in premature infants during the preoperative stay on neonatal ICU. They required more intensive care measures, such as more frequent inotropic support $(30.8 \%$ vs. $8.0 \%, p=0.035)$, mechanical ventilation $(76.9 \%$ vs. $37.9 \%, p=0.014)$, and red blood cell (RBC) transfusions $(46.2 \%$ vs. $10.3 \%, p=0.004)$. One premature infant born at $361 / 7$ weeks with suspected coarctation received diagnostic cardiac catheterization on day 7 , followed by coarctation repair on day 11 . Due to failure to thrive, ASO was performed on day 59 in this neonate. Three prematures died before receiving ASO. One infant born at 30 6/7 weeks developed extended NEC with multiple perforations in small intestine and colon on day 9 and died two days later. A premature born at 31 4/7 weeks developed mesenteric artery thrombosis and NEC on day 14 and died on day 20 , with large parts of intestine being gangrenous. One infant born at $326 / 7$ weeks, who received an interventional placement of a stent in the foramen ovale on day 40 due to decreasing oxygen saturations, required atrial septectomy on day 63 due to hypoxemia. This infant died on day 83 because of severe pulmonary hypertensive crises. Preoperative mortality was significantly increased in premature infants with D-TGA, as compared to term patients (23.1\% vs. $0.0 \%, p=0.002$ ). No patient in the entire cohort received inotropic support or mechanical ventilation when transferred to the operating room for ASO (Table 3).

Weight at cardiac surgery was lower in preterm infants compared to term infants ( 2615 vs. $3420 \mathrm{~g}, p<0.001$ ), whereas age at surgery was similar in both groups ( $8.5 \mathrm{vs}$. 8.0 days, $p=0.616$ ). Prematures received more often transfusions of RBC ( $80.0 \%$ vs. $41.4 \%, p=0.040)$ and fresh frozen plasma $(70.0 \%$ vs. $34.5 \%, p=0.040)$ during the course of $\mathrm{CPB}$. One term infant with intramural coronary artery and heart failure could not be weaned from CPB (Table 4).

Delayed chest closure was performed significantly more often in prematures than term born infants $(70.0 \%$ vs. $33.7 \%, p=0.037)$. Duration of postoperative ventilation was longer in prematures ( $175 \mathrm{~h}$ vs. $106 \mathrm{~h}, p=0.038$ ). The 
Table 2 Cardiac anatomy and coronary artery pattern

\begin{tabular}{|c|c|c|c|}
\hline Variable & $\begin{array}{l}\text { Premature infants }(n=13) \\
\text { Patients }(\%)\end{array}$ & $\begin{array}{l}\text { Term neonates }(n=87) \\
\text { Patients }(\%)\end{array}$ & $p$ value \\
\hline \multicolumn{4}{|l|}{ Cardiac anatomy } \\
\hline Isolated D-TGA (Intact ventricular septum) & $9(69.2)$ & $55(63.2)$ & 0.765 \\
\hline D-TGA with associated lesions & $4(30.8)$ & $32(36.8)$ & 0.765 \\
\hline VSD & $3(23.1)$ & $20(23.0)$ & 1.000 \\
\hline VSD + DORV & $0(0.0)$ & $1(1.1)$ & 1.000 \\
\hline VSD + LVOTO & $0(0.0)$ & $1(1.1)$ & 1.000 \\
\hline $\mathrm{CoA}$ & $0(0.0)$ & $1(1.1)$ & 1.000 \\
\hline $\mathrm{CoA}+\mathrm{VSD}$ & $1(7.7)$ & $7(8.0)$ & 1.000 \\
\hline CoA + VSD + LVOTO & $0(0.0)$ & $1(1.1)$ & 1.000 \\
\hline $\mathrm{CoA}+\mathrm{VSD}+$ pulmonary stenosis & $0(0.0)$ & $1(1.1)$ & 1.000 \\
\hline Restrictive atrial septum $^{\mathrm{a}}$ & $1(7.7)$ & $2(2.3)$ & 0.345 \\
\hline Coronary artery pattern ${ }^{\mathrm{b}}$ & Premature infants $(n=10)$ & Term neonates $(n=87)$ & \\
\hline 1L,Cx;2R (usual) & $8(80.0)$ & $56(64.4)$ & 0.487 \\
\hline Coronary artery pattern other than usual & $2(20.0)$ & $31(35.6)$ & 0.487 \\
\hline \multicolumn{4}{|l|}{ Two coronary Ostia } \\
\hline 1L;2R,Cx (Cx from RCA) & $2(20.0)$ & $14(16.1)$ & 0.668 \\
\hline 1R;2L,Cx (inverted) & $0(0.0)$ & $4(4.6)$ & 1.000 \\
\hline 1L,R;2Cx (inverted RCA and Cx) & $0(0.0)$ & $3(3.4)$ & 1.000 \\
\hline Other coronary anomaly (two ostia) & $0(0.0)$ & $5(5.7)$ & 1.000 \\
\hline Two coronary ostia (total) & $10(100.0)$ & $82(94.3)$ & 1.000 \\
\hline \multicolumn{4}{|l|}{ Single coronary ostium } \\
\hline 2L,Cx,R (single RCA) & $0(0.0)$ & $4(4.6)$ & 1.000 \\
\hline 1L,Cx,R (single LCA) & $0(0.0)$ & $1(1.1)$ & 1.000 \\
\hline Single coronary ostium (total) & $0(0.0)$ & $5(5.7)$ & 1.000 \\
\hline \multicolumn{4}{|l|}{ Intramural coronary artery } \\
\hline Intramural LCA & $1(10.0)$ & $1(1.1)$ & 0.197 \\
\hline Intramural RCA & $0(0.0)$ & $1(1.1)$ & 1.000 \\
\hline Intramural coronary artery (total) & $1(10.0)$ & $2(2.3)$ & 0.281 \\
\hline
\end{tabular}

$C O A$ coarctation of the aorta, D-TGA dextro-transposition of the great arteries, $D O R V$ double-outlet right ventricle, $L C A$ left coronary artery, LVOTO left ventricular outflow tract obstruction, RCA right coronary artery, VSD ventricular septal defect

${ }^{a}$ One premature infant with VSD and two term born infants with isolated D-TGA

${ }^{\mathrm{b}}$ For those who received cardiac surgery (10 and 87 , respectively)

risk for venous thrombosis $(40.0 \%$ vs. $4.7 \%, p=0.004)$ was higher in premature infants and there was a trend toward more chylous effusions into thorax. Two out of three preterm infants with venous thrombosis of the superior vena cava had confirmed chylothorax. Although postoperative cardiac arrhythmias were observed in about $40 \%$ of both groups, no infant required pacemaker implantation. Two prematures who received postoperative ECMO therapy died during the postoperative course: One infant born at 35 0/7 weeks developed a right atrial thrombus formation and multiorgan failure following postoperative ECMO therapy. One infant born at $363 / 7$ weeks with intramural coronary artery could not be weaned successfully from ECMO due to cardiac failure. One term infant died 54 days after ASO because of severe bacterial and fungal sepsis.
Overall mortality during hospitalization was significantly increased in prematures with D-TGA $(38.5 \%$ vs. $2.3 \%, p<0.001)$ compared to term infants. Duration of postoperative and total hospitalization were increased in preterm infants with D-TGA (Table 5).

Gestational age (adjusted unit OR 0.383, 95\% CI $0.179-0.821, p=0.014)$ and presence of an intramural coronary artery (adjusted OR 620, 95\% CI 4-82 373, $p=0.010)$ were the only variables independently associated with mortality in the entire cohort in multivariable logistic regression analysis (Nagelkerke's R-squared $0.592)$. 
Table 3 Clinical management and co-morbidities prior to arterial switch operation

\begin{tabular}{|c|c|c|c|}
\hline Variable & $\begin{array}{l}\text { Premature infants }(n=13) \\
\text { Patients }(\%) \text { or median }(\mathrm{IQR})\end{array}$ & $\begin{array}{l}\text { Term neonates }(n=87) \\
\text { Patients }(\%) \text { or median (IQR) }\end{array}$ & $p$ value \\
\hline Temperature at NICU admission $\left({ }^{\circ} \mathrm{C}\right)^{\mathrm{a}}$ & $36.7(36.4-37.3)$ & $36.8(36.4-37.2)$ & 0.642 \\
\hline Prostaglandin E1 infusion & $13(100.0)$ & $87(100.0)$ & N/A \\
\hline Duration of prostaglandin E1 infusion (days) & $10.0(8.0-18.0)$ & $8.0(6.5-10.0)$ & 0.127 \\
\hline Balloon atrioseptostomy & $10(76.9)$ & $72(82.8)$ & 0.699 \\
\hline Age at balloon atrioseptostomy (days) & $1.0(1.0-1.0)$ & $1.0(1.0-1.0)$ & 0.291 \\
\hline Redo-balloon atrioseptostomy & $0(0.0)$ & $4(4.6)$ & 1.000 \\
\hline Surgery prior to arterial switch & $2(15.4)$ & $0(0.0)$ & 0.016 \\
\hline Coarctation repair before arterial switch & $1(7.7)$ & $0(0.0)$ & 0.244 \\
\hline Cardiopulmonary resuscitation & $0(0.0)$ & $4(4.6)$ & 1.000 \\
\hline Inotropic support & $4(30.8)$ & $7(8.0)$ & 0.035 \\
\hline Duration of inotropic support (days) & $1.0(1.0-6.0)$ & $1.0(1.0-1.0)$ & 0.207 \\
\hline Cardiac arrhythmia & $1(7.7)$ & $8(9.2)$ & 1.000 \\
\hline Red blood cell transfusion & $6(46.2)$ & $9(10.3)$ & 0.004 \\
\hline Oxygen supplementation & $10(76.9)$ & $47(54.0)$ & 0.144 \\
\hline Duration of oxygen supplementation (days) & $2.0(1.2-5.2)$ & $1.0(1.0-3.0)$ & 0.226 \\
\hline Respiratory support, non-invasive & $10(76.9)$ & $65(74.7)$ & 1.000 \\
\hline Duration of respiratory support (days) & $5.0(2.3-13.0)$ & $2.0(1.0-4.0)$ & 0.021 \\
\hline Mechanical ventilation & $10(76.9)$ & $33(37.9)$ & 0.014 \\
\hline Duration of mechanical ventilation (days) & $2.5(2.0-7.3)$ & $1.5(1.0-2.8)$ & 0.052 \\
\hline Pulmonary hypertension & $2(15.4)$ & $5(5.7)$ & 0.225 \\
\hline Duration of inhaled nitric oxide treatment (days) & $14.5(11.3-17.8)$ & $4.0(2.0-4.0)$ & 0.079 \\
\hline Caffeine & $7(53.8)$ & $14(16.1)$ & 0.005 \\
\hline Respiratory distress syndrome & $2(15.4)$ & $0(0.0)$ & 0.016 \\
\hline Administration of surfactant & $1(7.7)$ & $0(0.0)$ & 0.130 \\
\hline Early onset infection, suspected & $2(15.4)$ & $17(19.5)$ & 1.000 \\
\hline Late onset infection, suspected & $3(23.1)$ & $1(1.1)$ & 0.007 \\
\hline Antibiotic therapy & $9(69.2)$ & $37(42.5)$ & 0.083 \\
\hline Duration of antibiotic therapy (days) & $3.0(2.0-6.0)$ & $3.0(3.0-5.0)$ & 0.657 \\
\hline NEC $\geq$ Bell Stage 2 & $2(15.4)$ & $0(0.0)$ & 0.016 \\
\hline Bronchopulmonary dysplasia & $2(15.4)$ & $0(0.0)$ & 0.016 \\
\hline Intracranial hemorrhage & $0(0.0)$ & $0(0.0)$ & N/A \\
\hline Periventricular leukomalacia & $0(0.0)$ & $0(0.0)$ & N/A \\
\hline Seizures & $0(0.0)$ & $1(1.1)$ & 1.000 \\
\hline Retinopathy of prematurity & $0(0.0)$ & $0(0.0)$ & N/A \\
\hline Acute renal failure & $0(0.0)$ & $1(1.1)$ & 1.000 \\
\hline Death prior to arterial switch operation & $3(23.1)$ & $0(0.0)$ & 0.002 \\
\hline
\end{tabular}

$I Q R$ interquartile range, $N E C$ necrotizing enterocolitis, NICU neonatal intensive care unit, N/A not applicable

aThe following information (no. of infants) was missing: Temperature at NICU admission=1 in the "premature infants" group; Temperature at NICU admission $=1$ in the control group

\section{Discussion}

In this retrospective study, we analyzed the impact of prematurity on postnatal and perioperative clinical management, co-morbidities, and mortality in infants with D-TGA. Our results demonstrate the requirement of more intensive care measures, as well as the appearance of more co-morbidities in the delivery room, and during the entire perinatal and postoperative period. Mortality, in particular during the preoperative period, was notably increased in preterm infants.

Perinatal management prior to corrective surgery has not been the focus of studies on preterm infants with D-TGA so far. Similar Apgar values indicate that primary fetalto-neonatal transition during the first minutes of life is not fundamentally different in prematures, compared to term infants. However, we found a significantly higher rate of 
Table 4 Data on cardiac surgery

\begin{tabular}{lllr}
\hline Variable $^{\mathrm{a}}$ & $\begin{array}{l}\text { Premature infants }(n=10) \\
\text { Patients }(\%) \text { or median (IQR) }\end{array}$ & \multicolumn{2}{l}{$\begin{array}{l}\text { Term neonates }(n=87) \\
\text { Patients }(\%) \text { or median (IQR) }\end{array}$} \\
\hline Age at cardiac surgery (days) & $8.5(5.8-16.0)$ & $8.0(7.0-11.0)$ & 0.616 \\
Weight at surgery (g) & $2615(2452-2698)$ & $3420(3130-3748)$ & $<0.001$ \\
Aortic clamp time (min) & $107(92-118)$ & $101(93-115)$ & 0.652 \\
Cardiopulmonary bypass time (min) & $275(265-341)$ & $263(230-325)$ & 0.322 \\
Red blood cell transfusion & $8(80.0)$ & $36(41.4)$ & 0.040 \\
Fresh frozen plasma transfusion & $7(70.0)$ & $30(34.5)$ & 0.040 \\
Platelet transfusion & $2(20.0)$ & $4(4.7)$ & 0.117 \\
Intraoperative death & $0(0.0)$ & $1(1.1)$ & 1.000 \\
\hline
\end{tabular}

$I Q R$ interquartile range

${ }^{a}$ For those who received cardiac surgery (10 and 87 , respectively)

mechanical ventilation in the delivery room in prematures. Whether this difference was caused by a deterioration of the respiratory situation per se, by a more frequent elective intubation before performing balloon atrial septostomy, or both, remains unclear. Several delivery room management strategies for infants with critical CHD focus on the availability of urgent cardiac interventions such as balloon atrial septostomy [16]. Intubation and mechanical ventilation should likewise be anticipated and included in the delivery room management plan of premature infants with D-TGA.

During the preoperative period, $31 \%$ of premature infants with D-TGA required inotropic support, almost four times more than term born infants. Duration of inotropic support was short in both groups. In contrast, the study of Kim et al. reported that more than $40 \%$ of term born infants required preoperative inotropic support to augment cardiac output and maintain adequate systemic blood pressure, and inotropic support was associated with early postoperative mortality [17]. Due to the low number of patients, we found no significant association between inotropic support and morbidities. However, three premature infants developed NEC or pulmonary hypertensive crisis, thus required preoperative inotropes, and died before cardiac surgery. In children who survived the preoperative period, inotropic medication was not associated with mortality.

Almost every second preterm infant received RBC transfusions prior to ASO, compared to every tenth term born infant. Recently published recommendations on RBC transfusion in infants with CHD state that premature infants maintained on prostaglandin E1 before cardiac surgery may not tolerate anemia and require higher hemoglobin levels [18]. However, the proposed higher limit is not further specified, and premature infants with uncorrected D-TGA have not been included in transfusion trials so far. Even in premature infants without CHD, there is no consent on transfusion thresholds, and an association between RBC transfusions and neonatal morbidity or mortality is yet inconclusive [19].
Two premature infants developed NEC prior to ASO and one term born infant after cardiac surgery. Both preterm infants died shortly after diagnosis of NEC. Prematurity and presence of a complex CHD are risk factors for NEC and simultaneous occurrence of both even further increases the risk for NEC [20, 21]. In addition, RBC transfusions in term newborns with CHD are associated with development of NEC [22]. Prevention of NEC should be a major target in the management of premature infants with D-TGA and include feeding regimes and transfusion strategies. The preoperative period in preterm infants with D-TGA is highly critical and characterized by many further co-morbidities typical for prematurity, such as apnea of prematurity, respiratory distress syndrome, bronchopulmonary dysplasia and jaundice, a higher rate of suspected late onset infection, and increased mortality, in contrast to infants born at term.

Median age at cardiac surgery was similar in both groups, and weight at surgery was above $2000 \mathrm{~g}$ in all infants of our cohort. Recent data show that ASO can be performed safely in infants weighing as little as $2000 \mathrm{~g}$ and delaying repair to await further growth might not confer any benefit [11]. Higher rates of transfusion of $\mathrm{RBC}$ and fresh frozen plasma during $\mathrm{CPB}$ in preterm infants could be partly explained by hemodilution, as the ratio of CPB circuit volume to the child's blood volume becomes increasingly unfavorable with decreasing body weight. However, transfusion-free ASO has been shown to be feasible in a newborn with a body weight as little as $1700 \mathrm{~g}$ [23].

Although arterial lactate on postoperative admission to ICU was higher in premature than term born infants, cardiovascular support, as quantified by vasoactive-inotropic score, was comparable between both groups. However, maximum postoperative vasoactive-inotropic score was not correlated with length of hospitalization or mortality in neonates after congenital heart surgery [24]. The chest was left open liberally in infants with low body weight to mitigate hemodynamic instability. No difference was observed 
Table 5 Postoperative course, co-morbidities, and outcomes

\begin{tabular}{|c|c|c|c|}
\hline Variable $^{\mathrm{a}}$ & $\begin{array}{l}\text { Premature infants }(n=10) \\
\text { Patients }(\%) \text { or median (IQR) }\end{array}$ & $\begin{array}{l}\text { Term neonates }(n=86) \\
\text { Patients }(\%) \text { or median (IQR) }\end{array}$ & $p$ value \\
\hline Arterial $\mathrm{pH}$ on ICU admission ${ }^{\mathrm{b}}$ & $7.43(7.39-7.46)$ & $7.43(7.39-7.47)$ & 0.760 \\
\hline Arterial lactate on ICU admission $(\mathrm{mg} / \mathrm{dL})^{\mathrm{b}}$ & $34.5(22.5-43.0)$ & $21.5(18.0-26.0)$ & 0.007 \\
\hline Maximum VIS within $24 \mathrm{~h}$ after surgery ${ }^{\mathrm{b}}$ & $12.2(8.2-19.1)$ & $14.5(8.4-23.0)$ & 0.541 \\
\hline Lowest $\mathrm{ScvO}_{2}$ within $24 \mathrm{~h}$ after surgery $(\%)^{\mathrm{b}}$ & $46.7(35.4-55.0)$ & $50.5(43.3-59.1)$ & 0.300 \\
\hline Extracorporeal membrane oxygenation & $2(20.0)$ & $2(2.3)$ & 0.053 \\
\hline Delayed chest closure & $7(70.0)$ & $29(33.7)$ & 0.037 \\
\hline Myocardial infarction & $1(10.0)$ & $1(1.2)$ & 0.199 \\
\hline Cardiopulmonary resuscitation & $2(20.0)$ & $6(7.0)$ & 0.195 \\
\hline Cardiac arrhythmia & $4(40.0)$ & $35(40.7)$ & 1.000 \\
\hline Invasive mechanical ventilation (h) & $175(147-302)$ & $106(75-171)$ & 0.038 \\
\hline Duration of inotropic support (days) & $5.0(3.5-11.3)$ & $3.5(2.0-5.0)$ & 0.060 \\
\hline Sepsis, culture proven & $0(0.0)$ & $2(2.3)$ & 1.000 \\
\hline Pneumonia & $1(10.0)$ & $3(3.5)$ & 0.361 \\
\hline Pulmonary hypertension & $4(40.0)$ & $23(26.7)$ & 0.460 \\
\hline Duration of inhaled nitric oxide treatment (h) & 47 (29-94) & $65(26-100)$ & 0.609 \\
\hline Acute renal failure & $1(10.0)$ & $0(0.0)$ & 0.104 \\
\hline Chylous effusions into thorax & $5(50.0)$ & $18(20.9)$ & 0.056 \\
\hline Chylothorax requiring surgical intervention & $1(10.0)$ & $0(0.0)$ & 0.105 \\
\hline Diaphragm paresis & $0(0.0)$ & $1(1.2)$ & 1.000 \\
\hline NEC $\geq$ Bell Stage 2 & $0(0.0)$ & $1(1.2)$ & 1.000 \\
\hline Duration of parenteral nutrition (days) & $9.0(6.5-15.3)$ & $6.0(4.0-8.0)$ & 0.070 \\
\hline Seizures & $0(0.0)$ & $1(1.2)$ & 1.000 \\
\hline Intracranial hemorrhage & $2(20.0)$ & $2(2.3)$ & 0.053 \\
\hline Venous thrombosis & $4(40.0)$ & $4(4.7)$ & 0.004 \\
\hline Red blood cell transfusion & $9(90.0)$ & $70(81.4)$ & 0.686 \\
\hline Fresh frozen plasma transfusion & $7(70.0)$ & $43(50.0)$ & 0.321 \\
\hline Platelet transfusion & $2(20.0)$ & $11(12.8)$ & 0.621 \\
\hline Hemoglobin at discharge (g/dL) & $12.6(10.4-14.4)$ & $12.8(11.1-14.3)$ & 0.935 \\
\hline Postoperative mortality & $2(20.0)$ & $1(1.2)$ & 0.028 \\
\hline Postoperative outcome ${ }^{c}$ & Premature infants $(n=8)$ & Term neonates $(n=85)$ & \\
\hline Postoperative hospital stay in survivors (days) & $24(20-31)$ & $16(13-22)$ & 0.006 \\
\hline Duration of total hospitalization in survivors (days) & $35(29-70)$ & $26(22-31)$ & 0.014 \\
\hline Weight at discharge $(\mathrm{g})$ & $3025(2842-3550)$ & $3515(3260-3860)$ & 0.072 \\
\hline Mortality, overall $(n=100)$ & $5(38.5)$ & $2(2.3)$ & $<0.001$ \\
\hline
\end{tabular}

$I C U$ intensive care unit; IQR, interquartile range, $\mathrm{NEC}$ necrotizing enterocolitis, $\mathrm{Scv} \mathrm{O}_{2}$ central venous oxygen saturation, VIS vasoactive-inotropic score

${ }^{\text {a}}$ For those who survived cardiac surgery (10 and 86, respectively)

${ }^{\mathrm{b}}$ The following information (no. of infants) was missing: arterial $\mathrm{pH}$ on ICU admission $=2$, arterial lactate on ICU admission $=2$, maximum VIS within $24 \mathrm{~h}$ after surgery $=2$, lowest $\mathrm{ScvO}_{2}$ within $24 \mathrm{~h}$ after surgery $=2$ in the control group

${ }^{\mathrm{c}}$ For those who were discharged alive ( 8 and 85 , respectively)

in the risk for acute renal failure with the requirement of dialysis. In contrast, Ahlström et al. reported a significantly increased frequency of peritoneal dialysis in preterm infants after ASO [7]. The overall incidence of postoperative renal failure in our cohort was considerably lower than previously reported rates of up to $40 \%$ in newborns with D-TGA
[17]. Preterm infants had an increased risk of postoperative venous thrombosis and a trend toward higher rates of chylothorax. Reduced activity of the fibrinolytic system in prematures, as well as placement of central lines and CPB cannulas, can facilitate venous thrombus formation, which often remains undetected [25]. In addition, upper extremity 
vein thrombosis is associated with chylothorax development after pediatric cardiac surgery [26].

Apart from prematurity, intramural coronary artery was the only factor independently associated with overall mortality in our cohort. Previous studies investigating a potential association between intramural coronary artery and mortality report contradictory results $[9,27]$.

Prematurity significantly increased the risk for pre- and postoperative co-morbidities, length of hospitalization, and mortality in our cohort of newborns with D-TGA. This association of prematurity and poor postoperative outcome has been found in other studies. Cain et al. found prematurity to be the only variable associated with prolonged postoperative hospitalization in a cohort of 70 neonates with D-TGA [8]. Qamar reported that gestational age less than 36 weeks negatively impacts hospital survival of patients with D-TGA [9]. Curzon et al. reported a more than fourfold increased mortality rate in infants weighting less than $2500 \mathrm{~g}$ at the time of ASO [28]. Ahlström et al. found an association between prematurity and major postoperative morbidity, prolonged mechanical ventilation, and ICU stay [7]. In contrast, Anderson et al. found no association between earlier gestational age ( $<38$ weeks) and morbidity or mortality in D-TGA patients. However, their study included only infants of at least 36 weeks of gestational age [6].

Early corrective cardiac surgery before clinical deterioration is generally recommended, but increases the risk for adverse outcomes in prematures [12, 15, 29]. Besides improving treatment for preterm infants with D-TGA, prenatal counseling and obstetric interventions should target at decreasing the likelihood of premature delivery for infants with prenatal diagnosis of D-TGA, as a delay in delivery might substantially improve outcomes in these high-risk patients [30].

This study has several limitations, such as its retrospective character and the single institutional focus. Due to the small number of preterm infants with D-TGA, it was not possible to further divide prematures in different subgroups depending on the gestational age. Various treatments, such as postnatal intubation or perioperative RBC transfusion, were carried out when clinically indicated by the attending physicians, without clear institutional guidelines for the treatment of premature infants with DTGA due to a lack of evidence. It is therefore possible that practice variations occurred during the study period. The sample size and low overall rate of certain morbidities in our cohort might have precluded detection of the potential effect of prematurity on complications and morbidities. However, this is the first study to provide detailed analysis of treatment and co-morbidities between birth and corrective surgery in premature infants with D-TGA. In addition, we report on operative outcomes during the study period. Due to the high risk for complications, the management of the premature infant with D-TGA remains challenging. A multidisciplinary approach is recommended to provide optimal preoperative care in premature infants with DTGA, including neonatologists, intensive care physicians, and pediatric cardiologists. Further research is needed to better understand factors contributing to premature delivery, to improve clinical treatment, and to investigate the impact of prematurity-related co-morbidities on long-term developmental outcomes.

\section{Conclusion}

Physicians treating preterm infants with D-TGA should be aware of the high risk of postnatal and perioperative co-morbidities, anticipate corresponding problems, and consider appropriate treatment options at an early stage.

\section{Acknowledgements None.}

Author Contributions Vinzenz Boos designed the study, collected and analyzed the data, supervised data interpretation, drafted the first version of the manuscript, and revised the manuscript for important intellectual content. Christoph Bührer, Mi-Young Cho, and Joachim Photiadis contributed to the interpretation of data and critically revised the manuscript for important intellectual content. Felix Berger contributed to the study design and interpretation of data and critically revised the manuscript for important intellectual content. All authors approved the final manuscript as submitted and agree to be accountable for all aspects of the work.

Funding Open Access funding enabled and organized by Projekt DEAL. The authors have no source of funding to declare.

Data Availability The data that support the findings of this study are available upon reasonable request from the corresponding author [VB]. The data are not publicly available due to ethical restrictions, them containing information that could compromise research participant privacy/consent.

Code Availability Not applicable.

\section{Declarations}

Conflict of interest On behalf of all the authors, the corresponding author states that there is no conflict of interest.

Consent to Participate Written informed consent of the study participants (or their parents or guardians) was not obtained, as all data were collected as part of routine clinical care and have been anonymized for the purpose of analysis and presentation.

Consent for Publication Publication of the results was approved by the Institutional Review Board (Charité Berlin, EA2/069/17).

Ethical approval Written informed consent of the study participants (or their parents or guardians) was not obtained, as all data were collected as part of routine clinical care and have been anonymized for the purpose of analysis and presentation. Publication of the results 
was approved by the Institutional Review Board (Charité Berlin, EA2/069/17).

Open Access This article is licensed under a Creative Commons Attribution 4.0 International License, which permits use, sharing, adaptation, distribution and reproduction in any medium or format, as long as you give appropriate credit to the original author(s) and the source, provide a link to the Creative Commons licence, and indicate if changes were made. The images or other third party material in this article are included in the article's Creative Commons licence, unless indicated otherwise in a credit line to the material. If material is not included in the article's Creative Commons licence and your intended use is not permitted by statutory regulation or exceeds the permitted use, you will need to obtain permission directly from the copyright holder. To view a copy of this licence, visit http://creativecommons.org/licenses/by/4.0/.

\section{References}

1. Tanner K, Sabrine N, Wren C (2005) Cardiovascular malformations among preterm infants. Pediatrics 116(6):e833-838. https://doi.org/10.1542/peds.2005-0397

2. Steurer MA, Baer RJ, Keller RL, Oltman S, Chambers CD, Norton ME, Peyvandi S, Rand L, Rajagopal S, Ryckman KK, Moon-Grady AJ, Jelliffe-Pawlowski LL (2017) Gestational age and outcomes in critical congenital heart disease. Pediatrics 140(4):e20170999. https://doi.org/10.1542/peds.2017-0999

3. Castellanos DA, Lopez KN, Salemi JL, Shamshirsaz AA, Wang Y, Morris SA (2020) Trends in preterm delivery among singleton gestations with critical congenital heart disease. J Pediatr 222:28-34.e4. https://doi.org/10.1016/j.jpeds.2020.03.003

4. Losay J, Touchot A, Serraf A, Litvinova A, Lambert V, Piot JD, Lacour-Gayet F, Capderou A, Planche C (2001) Late outcome after arterial switch operation for transposition of the great arteries. Circulation 18;104(12 Suppl 1):I121-I126. https:// doi.org/10.1161/hc37t1.094716

5. Fricke TA, d'Udekem Y, Richardson M, Thuys C, Dronavalli M, Ramsay JM, Wheaton G, Grigg LE, Brizard CP, Konstantinov IE (2012) Outcomes of the arterial switch operation for transposition of the great arteries: 25 years of experience. Ann Thorac Surg 94(1):139-145. https://doi.org/10.1016/j.athoracsur.2012. 03.019

6. Anderson BR, Ciarleglio AJ, Hayes DA, Quaegebeur JM, Vincent JA, Bacha EA (2014) Earlier arterial switch operation improves outcomes and reduces costs for neonates with transposition of the great arteries. J Am Coll Cardiol 63(5):481-487. https://doi.org/10.1016/j.jacc.2013.08.1645

7. Ahlström L, Odermarsky M, Malm T, Johansson Ramgren J, Hanseus K, Liuba P (2019) Surgical age and morbidity after arterial switch for transposition of the great arteries. Ann Thorac Surg 108(4):1242-1247. https://doi.org/10.1016/j.athor acsur.2019.04.033

8. Cain MT, Cao Y, Ghanayem NS, Simpson PM, Trapp K, Mitchell ME, Tweddell JS, Woods RK (2014) Transposition of the great arteries-outcomes and time interval of early neonatal repair. World J Pediatr Congenit Heart Surg 5(2):241-247. https://doi.org/10.1177/2150135113520559

9. Qamar ZA, Goldberg CS, Devaney EJ, Bove EL, Ohye RG (2007) Current risk factors and outcomes for the arterial switch operation. Ann Thorac Surg 84(3):871-878. https://doi.org/10. 1016/j.athoracsur.2007.04.102

10. Fraser CD Jr, Chacon-Portillo MA, Well A, Zea-Vera R, Binsalamah Z, Adachi I, Mery CM, Heinle JS (2020) Twenty-threeyear experience with the arterial switch operation: expectations and long-term outcomes. Semin Thorac Cardiovasc Surg 32(2):292-299. https://doi.org/10.1053/j.semtcvs.2020.01.004

11. Salna M, Chai PJ, Kalfa D, Nakamura Y, Krishnamurthy G, Quaegebeur JM, Najjar M, Shah A, Levasseur S, Anderson BR, Bacha EA (2019) Outcomes of the arterial switch operation in $\leq 2.5-\mathrm{kg}$ neonates. Semin Thorac Cardiovasc Surg. 31(3):488493. https://doi.org/10.1053/j.semtcvs.2018.03.007

12. Roussin R, Belli E, Bruniaux J, Demontoux S, Touchot A, Planché C, Serraf A (2007) Surgery for transposition of the great arteries in neonates weighing less than 2,000 grams: a consecutive series of 25 patients. Ann Thorac Surg 83(1):173-177. https://doi.org/10.1016/j.athoracsur.2006.07.042

13. Axelrod DM, Chock VY, Reddy VM (2016) Management of the preterm infant with congenital heart disease. Clin Perinatol 43(1):157-171. https://doi.org/10.1016/j.clp.2015.11.011

14. Cheng HH, Almodovar MC, Laussen PC, Wypij D, Polito A, Brown DW, Emani SM, Pigula FA, Allan CK, Costello JM (2011) Outcomes and risk factors for mortality in premature neonates with critical congenital heart disease. Pediatr Cardiol 32(8):1139-1146. https://doi.org/10.1007/s00246-011-0036-3

15. Dollat C, Vergnat M, Laux D, Stos B, Baruteau A, Capderou A, Demontoux S, Hamann M, Mokhfi E, Van Aerschot I, Roussin R, Le Bret E, Ly M, Belli E, Lambert V (2015) Critical congenital heart diseases in preterm neonates: is early cardiac surgery quite reasonable? Pediatr Cardiol 36(6):1279-1286. https://doi. org/10.1007/s00246-015-1158-9

16. Słodki M, Respondek-Liberska M, Pruetz JD, Donofrio MT (2016) Fetal cardiology: changing the definition of critical heart disease in the newborn. J Perinatol 36(8):575-580. https://doi. org/10.1038/jp.2016.20

17. Kim JW, Gwak M, Shin WJ, Kim HJ, Yu JJ, Park PH (2015) Preoperative factors as a predictor for early postoperative outcomes after repair of congenital transposition of the great arteries. Pediatr Cardiol 36(3):537-542. https://doi.org/10.1007/ s00246-014-1046-8

18. Cholette JM, Willems A, Valentine SL, Bateman ST, Schwartz SM (2018) Recommendations on RBC transfusion in infants and children with acquired and congenital heart disease from the pediatric critical care transfusion and anemia expertise initiative. Pediatr Crit Care Med. 19(9S Suppl 1):S137-S148. https:// doi.org/10.1097/pcc.0000000000001603

19. Crawford TM, Andersen CC, Hodyl NA, Robertson SA, Stark MJ (2019) The contribution of red blood cell transfusion to neonatal morbidity and mortality. J Paediatr Child Health 55(4):387-392. https://doi.org/10.1111/jpc.14402

20. Neu J, Walker WA (2011) Necrotizing enterocolitis. N Engl J Med 364(3):255-264. https://doi.org/10.1056/nejmra1005408

21. Motta C, Scott W, Mahony L, Koch J, Wyckoff M, Reisch J, Burchfield PJ, Brion LP (2015) The association of congenital heart disease with necrotizing enterocolitis in preterm infants: a birth cohort study. J Perinatol 35(11):949-953. https://doi.org/ 10.1038/jp.2015.96

22. Baxi AC, Josephson CD, Iannucci GJ, Mahle WT (2014) Necrotizing enterocolitis in infants with congenital heart disease: the role of red blood cell transfusions. Pediatr Cardiol 35(6):1024-1029. https://doi.org/10.1007/s00246-014-0891-9

23. Huebler M, Redlin M, Boettcher W, Koster A, Berger F, Peters B, Hetzer R (2008) Transfusion-free arterial switch operation in a $1.7-\mathrm{kg}$ premature neonate using a new miniature cardiopulmonary bypass system. J Card Surg 23(4):358-360. https://doi. org/10.1111/j.1540-8191.2007.00555.x

24. Butts RJ, Scheurer MA, Atz AM, Zyblewski SC, Hulsey TC, Bradley SM, Graham EM (2012) Comparison of maximum vasoactive inotropic score and low cardiac output syndrome as markers of early postoperative outcomes after neonatal cardiac 
surgery. Pediatr Cardiol 33(4):633-638. https://doi.org/10.1007/ s00246-012-0193-z

25. Yang JY, Chan AK (2010) Neonatal systemic venous thrombosis. Thromb Res 126(6):471-476. https://doi.org/10.1016/j. thromres.2010.10.009

26. Perry T, Bora K, Bakar A, Meyer DB, Sweberg T (2020) Nonsurgical risk factors for the development of chylothorax in children after cardiac surgery-does fluid matter? Pediatr Cardiol 41(1):194-200. https://doi.org/10.1007/s00246-019-02255-4

27. Pasquali SK, Hasselblad V, Li JS, Kong DF, Sanders SP (2002) Coronary artery pattern and outcome of arterial switch operation for transposition of the great arteries: a meta-analysis. Circulation 106(20):2575-2580. https://doi.org/10.1161/01.cir. $0000036745.19310 . b b$

28. Curzon CL, Milford-Beland S, Li JS, O’Brien SM, Jacobs JP, Jacobs ML, Welke KF, Lodge AJ, Peterson ED, Jaggers J (2008) Cardiac surgery in infants with low birth weight is associated with increased mortality: analysis of the Society of Thoracic Surgeons Congenital Heart Database. J Thorac Cardiovasc Surg 135(3):546-551. https://doi.org/10.1016/j.jtcvs.2007.09.068

29. Soongswang J, Adatia I, Newman C, Smallhorn JF, Williams WG, Freedom RM (1998) Mortality in potential arterial switch candidates with transposition of the great arteries. J Am Coll Cardiol 32(3):753-757. https://doi.org/10.1016/s0735-1097(98)00310-6

30. Chu PY, Li JS, Kosinski AS, Hornik CP, Hill KD (2017) Congenital heart disease in premature infants $25-32$ weeks' gestational age. J Pediatr 181:37-41.e1. https://doi.org/10.1016/j.jpeds.2016. 10.033

Publisher's Note Springer Nature remains neutral with regard to jurisdictional claims in published maps and institutional affiliations. 